\title{
THU0571 PRELIMINARY RESPONSE TO JANUS KINASE INHIBITION WITH BARICITINIB IN CHRONIC ATYPICAL NEUTROPHILIC DERMATOSIS WITH LIPODYSTROPHY AND ELEVATED TEMPERATURES (CANDLE)
}

G.A. Montealegre ${ }^{1}$, A. Reinhardt ${ }^{2}$, P. Brogan ${ }^{3}$, Y. Berkun ${ }^{4}$, A. Zlotogorski ${ }^{4}$ D. Brown ${ }^{5}$, L. Gao ${ }^{6}$, J.A. Dare ${ }^{6}$, S. Schalm ${ }^{7}$, T.L. Klausmeier ${ }^{8}$, S. Murias ${ }^{9}$ D. Chapelle ${ }^{1}$, H. Kim ${ }^{1}$, S. Judd ${ }^{1}$, M. O'Brien ${ }^{1}$, A.A. de Jesus ${ }^{1}$, B. Kost ${ }^{1}$, S.M. Paul ${ }^{10}$, R.A. Colbert ${ }^{1}$, A. Brofferio ${ }^{11}$, C. Lee ${ }^{12}$, C. Hadigan ${ }^{13}$, T. Heller ${ }^{14}$, M. Waldman ${ }^{14}$, K.I. Rother ${ }^{14}$, R. Goldbach-Mansky ${ }^{1} .{ }^{1}$ NIH/NIAMS, Bethesda; ${ }^{2}$ Children's Hospital of Omaha, Omaha, United States; ${ }^{3}$ Great Ormond Street Hospital, London, United Kingdom; ${ }^{4}$ Hadassah-Hebrew University Medical Center, Jerusalem, Israel; ${ }^{5}$ Children's Hospital Los Angeles, Los Angeles; ${ }^{6}$ University of Arkansas for Medical Sciences, Little Rock, United States; ${ }^{7}$ LMU Munich, Munich, Germany; ${ }^{8}$ Riley Hospital for Children, Indianapolis, United States; ${ }^{9}$ Hospital Infantil La Paz, Madrid, Spain; ${ }^{10} \mathrm{NIH} / \mathrm{CC}$; ${ }^{11} \mathrm{NIH} / \mathrm{NHLBI}$; ${ }^{12} \mathrm{NIH} / \mathrm{NCl} ;{ }^{13} \mathrm{NIH} / \mathrm{NIAID} ;{ }^{14} \mathrm{NIH} / \mathrm{NIDDK}$, Bethesda, United States

Background: Elevated serum IP-10 (CXCL10) levels and gene expression studies showing a prominent "interferon (IFN) signature" suggested modulation of IFN signaling might be a therapeutic option in CANDLE patients.

Objectives: The objective of this compassionate use program is to provide baricitinib (JAK1/JAK2 inhibitor) to CANDLE patients who have no other comparable or satisfactory treatment options. Potential efficacy of treatment was assessed by a reduction in mean Autoinflammatory Diary Scores (ADS) to $<0.5$ and reduction of steroid doses by at least $50 \%$ in patients receiving steroids at baseline.

Methods: Paired t-test was used to compare mean ADS and prednisone doses at the last $\mathrm{NIH}$ clinic visit to baseline data.

Results: Between October 2011 and January 1st, 2016, 11 CANDLE patients have been treated (mean duration 2.5 years $(S D \pm 1)$ ). 9 of 11 patients achieved an ADS of $<0.5$ at the time of their last visit (mean ADS decreased from $1.3 \pm$ 0.8 at baseline to $0.2 \pm 0 \mid 3)(p<0.005), 8$ of 10 patients achieved a reduction in steroids doses $>$ than $50 \%$ from baseline (mean total prednisone dose decreased from $0.8 \mathrm{mg} / \mathrm{kg} /$ day $(0.2-1.8)$ to $0.2 \mathrm{mg} / \mathrm{kg} /$ day $(0-1.1))(\mathrm{p}<0.005)$, 4 patients discontinued prednisone completely. The mean dose of baricitinib at the last patient visit was $6.9 \pm 2.8 \mathrm{mg} /$ day. 7 patients reported at least 1 serious adverse event (SAE), infection being the most common. 2 patients have been discontinued due to SAEs (avascular necrosis; BK viremia and azotemia). 1 patient required temporary interruption of baricitinib due to neutropenia, and 3 other patients had their dose electively reduced after testing positive for BK viremia: patients were asymptomatic. The most common adverse events were upper respiratory infections, cough, and BK viruria (baseline BK virus screening was not performed). 1 patient died due to worsening interstitial lung disease with development of respiratory failure 4 months after discontinuation of baricitinib and initiation of another JAK inhibitor.

Conclusions: Preliminary efficacy data in 11 CANDLE patients treated with baricitinib are encouraging and suggest that targeting IFN signaling with a JAK1/JAK2 inhibitor may be a successful therapeutic strategy. Monitoring BK viral titers in blood and urine, in addition to other measures of safety and efficacy, may be important in dose selection and the benefit-risk assessment of baricitinib for CANDLE patients.

Disclosure of Interest: G. Montealegre: None declared, A. Reinhardt: None declared, P. Brogan: None declared, Y. Berkun: None declared, A. Zlotogorski: None declared, D. Brown: None declared, L. Gao: None declared, J. Dare: None declared, S. Schalm: None declared, T. Klausmeier: None declared, S. Murias: None declared, D. Chapelle: None declared, H. Kim: None declared, S. Judd: None declared, M. O'Brien: None declared, A. de Jesus: None declared, B. Kost: None declared, S. Paul: None declared, R. Colbert Grant/research support from: CRADA (NIH -Eli Lilly), A. Brofferio: None declared, C. Lee: None declared, C. 
Hadigan: None declared, T. Heller: None declared, M. Waldman: None declared,

K. Rother: None declared, R. Goldbach-Mansky: None declared

DOI: 10.1136/annrheumdis-2016-eular.2810 